\title{
Topical Myristyl Nicotinate Cream
}

National Cancer Institute

\section{Source}

National Cancer Institute. Topical Myristyl Nicotinate Cream. NCI Thesaurus. Code C78469.

A topical cream containing the ester prodrug myristyl nicotinate (MN), a lipophilic nicotinic acid derivative with potential chemopreventive activity. Upon topical application, myristyl nicotinate penetrates into the epidermis where the agent is cleaved and is converted into nicotinic acid (niacin); nicotinic acid then diffuses into cells where it is converted to nicotinamide adenine dinucleotide (NAD). NAD may stimulate poly(ADP-ribose) polymerase-1 (PARP-1); enhance skin cell turnover and epidermal differentiation; and strengthen skin barrier function. NAD is a coenzyme that plays a crucial role in many redox reactions; PARP-1 is an enzyme that plays an important role in DNA repair. 